\title{
The Long-Term Mechanism of Extracurricular Activities in Primary and Secondary Schools: Using the Four Festivals and One Party in Huai'an No.1 Mountain Middle School as a Case Study
}

\author{
Changshun Sun \\ Huai'an No.1 Mountain Middle School, Huai'an, Jiangsu, China
}

\begin{abstract}
Extracurricular activities play a significant part in students' overall development, and the long-term mechanism is critical to extracurricular activities' educational efficiency. This paper describes Huai'an No. 1 Mountain Middle School's regular extracurricular events, which include four festivals and one party, as well as the tactics used to create a long-term mechanism for the school's extracurricular activities.
\end{abstract}

Science Insights Education Frontiers 2022; 11(1):1517-1521.

Doi: 10.15354/sief.22.or011

How to Cite: Sun, C. (2022). The long-term mechanism of extracurricular activities in primary and secondary schools: Using the four festivals and one party in Huai'an No.1 Mountain Middle School as a case study. Science Insights Education Frontiers, 11(1):1517-1521.

Keywords: Long-Term Mechanism, Extracurricular Activities, Festivals, Primary and Secondary Schools

Correspondence to: Changshun Sun, Huai'an No.1 Mountain Middle School, Huai'an, Jiangsu, China. E-mail: sdclsunchangshun@163.com

Conflict of Interests: None. 


\section{Introduction}

$\mathrm{E}$ XTRACURRICULAR activities are critical for the achievement of a wellrounded education. They contribute significantly to the development of school culture, the enhancement of students' overall competency, and their adaptation to society. The use of long-term mechanisms in extracurricular activities is a novel experiment in the new curriculum reform, with the goal of resolving issues with current extracurricular activities such as short length, lack of aims, and arbitrariness (Feng, 2016). In this context, Huai'an No.1 Mountain Middle School of the 271 Education Group establishes a long-term mechanism for its regularized extracurricular activities, which include a sports festival, a science and technological festival, a reading festival, an art festival, and a New Year party (collectively, the four festivals and one party), which serve as theoretical and practical references for the school and its peers. The purpose of this article is to provide a quick overview of the four festivals and one party, as well as to analyze the tactics used by the school to develop a long-term mechanism for extracurricular events.

\section{A Conceptual Examination of the Long-Term Mecha- nism by which Extracurricular Activities Operate}

\section{Connotations}

The phrase "long-term mechanism" refers to the structure that supports a system's regular operation and functional performance over an extended period of time. The longterm mechanism of extracurricular activities is a school management system that organizes and standardizes extracurricular practical activities in order to accomplish particular goals. Long-term relates to the system's permanence and longevity, whereas mechanism refers to the system's integration of extracurricular activities. That is not to say that the long-term mechanism is unchangeable; rather, it will be refined and developed through time and in response to changing circumstances.

\section{Extracurricular Activities that have Long-Term Mech- anisms}

Persistent and vital extracurricular activities are those that have long-term mechanisms. Persistent activity is defined as activity that continues in terms of time and effect. For

(C) 2022 Insights Publisher. All rights reserved.

Creative Commons NonCommercial CC BY-NC: This article is distributed under the terms of the Creative Commons Attribution-NonCommercial 4.0 License (http://www.creativecommons.org/licenses/by$\mathrm{nc} / 4.0 /$ ) which permits non-commercial use, reproduction and distribution of the work without further permission provided the original work is attributed by the Insights Publisher. 
instance, the reading festival at Huai'an No.1 Mountain Middle School is not timebound. Reading is encouraged at all times to augment classroom instruction and help students widen their horizons of knowledge. Through flexible time management, extracurricular activities can be extended and their impacts amplified. Extracurricular activities with long-term processes are vital since they are integral to kids' holistic education and have specific purposes.

\section{An Investigation of the Long-Term Process by which Extracurricular Activities Operate}

Huai'an No.1 Mountain Middle School, a member of the 271 Education Group, has a long history of organizing significant extracurricular activities that encourage students' overall development. It has been dedicated to optimizing the long-term mechanism for extracurricular events, particularly the four festivals and one party, over the years.

\section{The Four Festivals and One Party are Summarized}

Preparation for the sports festival takes six weeks, during which students select sports, prepare essential equipment, write competition regulations, and arrange for the sports field. The entire exercise necessitates a variety of management abilities, including goal formulation and progress tracking.

The science and technology festival is divided into four sections: popularization of science, experimentation, model construction, and competition. The substance of activities varies according to the stage of learning. The activities in scientific popularization and experimentation are designed to match the knowledge students acquire in mathematics, physics, biology, and chemistry, allowing students to apply classroom knowledge to campus activities. Each segment is assigned a significant theme by the teacher. For example, they introduce junior secondary students to the application of block robot building and artificial intelligence in education so that students gain a basic understanding of how cutting-edge science is applied; senior secondary students work on projects involving more sophisticated subjects such as cloud computing.

The Reading Festival strives to broaden students' reading lists, encourage their enthusiasm for reading, and foster a knowledge-based campus culture conducive to reading. This practice broadens students' knowledge of books and introduces them to a vibrant world represented by books, which encourages students' independent reading and exploration.

Through the spiritual value of art, the art festival aims to modify, improve, and grow students' spiritual lives. It lasts six weeks. The primary components are music and art. This practice helps students develop their aesthetic ability, artistic vision, and ability to express themselves uniquely.

The purpose of the New Year's Eve celebration is to commemorate New Year's Day and usher in the New Year. Additionally, it aims to encourage cultural and creative events at the school, enrich the campus's cultural life, and offer students a plat- 
form to showcase their abilities. The activity will last four weeks. Initially, the school held the party on the evening of December 31, but gradually expanded the festival to include pre-party preparation, performance selection for the talent show, and rehearsal preparations, among other things.

\section{Strategies for Building the Long-Term Mechanism of Extracurricular Activities}

\section{Combining Extracurricular Activities with Curricular Content}

The content of activities is critical in establishing a long-term mechanism for extracurricular activities. To maintain the sustainability of extracurricular activities, Huai'an No.1 Mountain Middle School uses a close correlation between extracurricular activities and curriculum material as a selection criterion. For example, in the reading festival, integrating after-class reading with textbook content is critical for maintaining students' extensive reading and cultivating their passion for reading. Additionally, the reading festival's activities extend beyond book reading to include calligraphy production and appreciation of cinema and television adaptations of literary masterpieces. Students read not only Chinese books but also those written in English. Students gain an appreciation for the diversity of the book world and develop a lifelong habit of reading as a result of their exposure to a wide variety of works.

\section{Standardizing Patterns for Extracurricular Activities}

In most schools today, extracurricular activities include procedures such as objective setting, post-activity summaries, and reporting on individual results. They lack, however, specification of activity design and implementation, resulting in the absence of activity uniqueness and haphazard process structure. Huai'an No. 1 Mountain Middle School addresses this issue by defining patterns for extracurricular activities in terms of duration, content, and processes. A structure of different extracurricular activities, including four festivals and one party, is in place to help students develop holistically.

\section{Encourage Students' Autonomous Participation}

In traditional education, students typically participate passively in teacher-designed extracurricular activities. Nonetheless, a genuine educational activity places a premium on students' autonomy. At Huai'an No.1 Mountain Middle School, students are actively involved in all aspects of extracurricular activity design and implementation, from aim setting to topic selection and organization. The activities are designed with the students' interests and internal needs in mind. Extracurricular activities are also designed to help kids improve their ability to self-regulate, their knowledge of their responsibilities, and 
their problem-solving abilities. Proactive participation in an activity with self-identified goals helps children develop their creativity and initiative.

\section{Optimizing Collaborative Mechanisms for Extracurric- ular Activities}

At Huai'an No. 1 Mountain Middle School, assessments are conducted at the school and grade levels to determine the effectiveness of extracurricular activities. Planners and organizers maintain adequate communication with classroom teachers to ensure that extracurricular events are designed in such a way that all students are engaged and accomplish the objectives (Wang, 2011).

\section{Reflection and Prospective}

We discovered several issues during our study of extracurricular activities at Huai'an No.1 Mountain Middle School. In terms of actual application, students' organizational skills must be strengthened. At the moment, the school organizes extracurricular activities using a regular schedule of four festivals and one party. Teachers and students alike lack the capacity to create additional activities. Additionally, effective extracurricular education requires supportive activity venues. Currently, the educational facilities of institutions chosen by the school for off-campus activities require improvement. The school should use greater caution in selecting locations for extracurricular activities. Collaboration with other schools to establish permanent locations for extracurricular activities is an option worth investigating. Thus, there is still potential for development in the long-term mechanism of the school's extracurricular activities, and instructors and students are expected to do further research on this subject.

\section{References}

Feng, Y.G. (2016). The long-term mechanism of extracurricular sports clubs in colleges and universities in Zhejiang Province: Citing Zhejiang Shuren University as a case study. Contemporary Sports Technology, 2016(6): 123-124. DOI: https://doi.org/10.16655/j.cnki. 20952813.2016.06.123

Wang, W.Z. (2011). The construction of longterm mechanism of college student volunteer service. Leading Journal of Ideological \& Theoretical Education, 2011(2):106-110. 

Sun (China). Mechanism of Extracurricular Activities in Primary and Secondary Schools. 